\title{
NOVA VARIEDADE DE MENTA ARVENSIS (1)
}

Abelardo Rodrigues Lma, engenheiro agrônomo, Seçẫo de Fumo, Plantas Medicinais $e$ Inseticidas, Instituto Agronómico de Campinas, e Terence R. M. Moluan, engenheiro quimico, Instituto de Pesquisas Tecnologicas de São Paulo

\section{1 - INTRODUÇÃO}

A menta japonêsa (Mentha arvensis L. subsp. haplocalix Briquet var. piperascens Holmes ou forma piperascens Malinvaud), foi introduzida do Japão por emigrantes que trouxeram pequena quantidade de rizomas da preciosa planta. A sua disseminação foi lenta, mas, por volta de 1931 ou 1932, já existiam culturas comerciais e eram vendidas pequenas partidas de mentol (3).

Em conseqüência da guerra sino-japonêsa e da segunda guerra mundial, acentuou-se nos mercados americanos e europeus, a partir de 1938, sensível escassez de mentol e óleo de menta arvensis. Promoveu-se, por essa ocasião, o desenvolvimento de novos centros de produção, dentre os quais se destacou o Brasil, ou, mais exatamente, o Estado de São Paulo, onde agricultores japonêses, familiarizados com a cultura na sua terra natal, vinham fazendo pequenas plantaçóes e, graças aos bons resultados colhidos desde o início, não tiveram dificuldades em ampliá-las. Aliás, a aclimação dessa labiada, ao nosso ambiente, processou-se com extraordinária rapidez, encontrando, nas terras virgens, arenosas barrentas da formação BauruSuperior, condições ideais para a sua vegetação.

A cultura da menta japonêsa se estendeu enormemente, de $1940 \mathrm{em}$ diante, para atingir, em 1945, uma área de mais de 25.000 hectares e uma produção superior a 1.200 toneladas de óleo. Com o término da guerra, sobreveio a queda dos preços, a qual chegou justamente quando maior era a produção, acarretando grandes prejuízos e o colapso da cultura. Alguns anos depois, os preços tiveram alguma melhora e a produção reagiu moderadamente, chegando ao nível de 150-200 toneladas de óleo. Os lavradores, porém, se queixavam da diminuição do rendimento, em virtude da escassez das terras virgens e do ataque das moléstias, principalmente da ferrugem.

A criação de uma nova variedade, mais produtiva e mais resistente à ferrugem, seria oportuna, pois viria dar novo alento à cultura e tornar possível uma produção econômicamente rendosa e capaz de enfrentar os preços de concorrência no mercado internacional. A julgar pelos resultados colhidos atê agora, a menta Campinas - M. A. 701 veio desempenhar êsse valioso papel.

(1) Apresentado a Segunda Reuniåo Latino-Americana de Fitogeneticistas e Fitoparasitologistas, realizada em Såo Paulo, Piracicaba e Campinas, de 31 de março a 8 de abril de 1952. 


\section{2-OBTENÇÃO E SELEÇÃO DE "SEEDLINGS"}

Em abril de 1944, demos início ao estudo de "seedlings" de menta japonêsa, utilizando sementes obtidas em pequenos lotes cultivados na Estação Experimental Central de Campinas. Tínhamos conhecimento de que essa menta era heterozigota, sendo o aspecto uniforme da cultura resultado apenas do sistema normal de multiplicação em que se utilizam os rizomas, portanto, via vegetativa (2). A grande variação apresentada pelos "seedlings" não só veio confirmar aquela informação como endossar as nossas esperanças de encontrar formas de maior valor econômico. Constatamos variações nos caracteres botânicos, tais como : porte da planta ; tamanho, grossura e coloração das hastes ; dimensões, coloração e pilosidado das fôlhas ; coloração das flores, modo de florescimento, tamanho e disposição das espigas, época de floração, fertilidade das flores, etc.

A nossa atenção se concentrou principalmente nos caracteres de rusticidade, produtividade, resistência às moléstias e qualidade do óleo essencial produzido.

Em 1947, dentre algumas centenas de "seedlings", selecionamos diversos e, entre êles, o M. A. 701. Esste "seedling" destacou-se logo pela sua rusticidade e resistência a ferrugem. Posteriormente, foram-se patenteando as outras qualidades que o caracterizam como ótimo produtor de essência.

O "seedling" M. A. 701 se apresenta com todos os caracteres de uma nova variedade de Mentha arvensis. Distingue-se pelo seu porte menos ereto, em virtude da grande ramificação das hastes; pelas fôlhas ovalacuminadas, denticuladas, recobertas de densa pilosidade, máxime na pám gina inferior; essa pubescência confere um tom opalescente ao conjunto da folhagem ; as hastes novas são verde-claras, coloração que, com a idade, muda para avermelhada; também elas são revestidas de pêlos brancos que lhes conferem tom brancacento ; a corola é branca e protegida por sépalas e brácteas grandes que persistem verdes muitos dias após a queda das pétalas ; as flores são estéreis ; os rizomas são fortes e providos de rấzes longas.

\section{3-CARACTERISTICAS DO "SEEDLING" CAMPINAS M. A. 701}

\section{1 - PRODUTIVIDADE}

Um dos primeiros "seedlings" por nós selecionados, o M. A. 3, tem sido cultivado desde 1947, na região de Presidente Prudente, dando boas produçôes, cêrca de 20 a 30\% superiores às da menta japonêsa comum, segundo opinião dos próprios lavradores. Em Campinas, fizemos um pequeno ensajo comparativo de produção entre o M. A. 701 e o M. A. 3, não incluindo a menta comum, por falta de mudas.

Os resultados, conforme se pode constatar no quadro 1, são tão expressivos que dispensam comentários. 
Quadro 1.-Produção de óleo obtida, em duas colheitas, com o "seedling" M. A. 701, comparada, em ensaio, à de outro anteriormente cultivado no Estado

\begin{tabular}{|c|c|c|c|c|c|c|c|c|c|}
\hline \multirow{2}{*}{ Variedades } & \multicolumn{3}{|c|}{ 1..$^{\circ}$ corte -4 jan. 49} & \multicolumn{3}{|c|}{ 2.0 corte- 6 abril 49} & \multicolumn{3}{|c|}{ Total } \\
\hline & Hectare & Alqueire & $\begin{array}{l}\text { Numerc } \\
\text { fndice }\end{array}$ & Hectare & Alqueire & $\begin{array}{l}\text { Número } \\
\text { fndice }\end{array}$ & Hectare & Alqueire & $\begin{array}{l}\text { Número } \\
\text { f́ndice }\end{array}$ \\
\hline & $k e$ & $k g$ & no. & $k g$ & $k g$ & no. & $\mathrm{kg}$ & $k g$ & no. \\
\hline M. A. - 701 & 60,3 & 146,0 & 206 & 132,1 & 319,8 & 251 & 192,5 & 465,8 & 235 \\
\hline M. A. $-3-$ (Testemu- & 29,3 & 71,0 & 100 & 52,6 & 127,4 & 100 & 82,0 & 188,4 & 100 \\
\hline Diferenças - - & 31,0 & 75,0 & 106 & 79,5 & 192,4 & 151 & 110,5 & 267,4 & 135 \\
\hline
\end{tabular}

Convém registrar o fato de têrmos de aparar as ramas do M. A. 701, para impedir que elas invadissem os canteiros vizinhos do M. A. 3. Na última safra, 1949-50, em Presidente Prudente, em plantações do M. A. 701 houve rendimentos de $186 \mathrm{~kg}$ de óleo por hectare, ou $450 \mathrm{~kg}$ por alqueire $\left(24.200 \mathrm{~m}^{2}\right)$, em duas colheitas ou cortes, confirmando-se, em escala comercial, o que foi obtido em Campinas, em culturas experimentais.

\section{2 - RESISTÊNCIA À SÊCA}

Prova muito simples da resistência à sêca foi obtida nos canteiros do já citado ensaio de produtividade entre o M. A. 3 e M. A. 701. Depois da colheita, que se efetuou em abril de 1949, os canteiros foram conservados intactos e, após as chuvas de outubro e novembro, constatou-se o seguinte : todos os canteiros da menta M. A. 701 estavam bem brotados, ao passo que nenhuma planta apareceu nos canteiros da menta M. A. 3. Os dados de chuva registrados foram : de 16 de outubro a 5 de setembro, $0 \mathrm{~mm}$; dias 5,14 e 22 de setembro, $2 \mathrm{~mm}$; dia 6 de outubro, $12 \mathrm{~mm}$.

\section{3 - RESISTÊNCIA À FERRUGEM}

A ferrugem (Puccinia menthae Pers.) acha-se muito difundida, e as suas infestações ocorrem em caráter endêmico na maioria das plantaçóes de menta do Estado de São Paulo. Os ataques assumem maior gravidade durante os meses de outono, quando a temperatura entra em declínio e as chuvas vão escasseando. Não significa, porém, ausência de infestações severas nos meses chuvosos de verão, sendo frequentes os danos de monta nos períodos de estiagem que ocorrem nessa estação. $O$ combate, pelo emprêgo de fungicidas, é de difícil execução, tanto em consequência do possível efeito prejudicial sôbre a qualidade do óleo, como do custo e da eficácia relativa dêsse meio de defesa. A resistência natural da variedade representa - recurso ideal de que se tenta lançar mão, sempre que para isso haja possibilidade. 
Dos numerosos "seedlings" observados até agora, nenhum se conservou imune à ferrugem. Um dêles, aliás sem valor, mostrou-se imune durante três anos, porém, depois disso, foi atacado, como se tivesse aparecido uma nova linhagem de Puccinia, capaz de parasitá-lo. Expressamo-nos nesses têrmos, porque, embora não tenha havido estudo fitopatológico para comprovação e explanação dos fatos registrados, tal ocorrência é frequente na biologia das Puccinias.

Com referência à menta M. A. 701, temos observado que o ataque da ferrugem é retardado por certo grau de resistência e que as pústulas formadas são menores e a crestação e queda das fôlhas ocorrem lentamente, atenuando os prejuízos causados pelo fungo.

\section{4 - INFLUÊNCIA DA ÉPOCA DA COLHEITA}

Para os cultivadores de menta, é preceito conhecido que a colheita deva ser feita na ocasião em que a erva tenha atingido plena florescência. Nessa fase, o óleo essencial não só é mais abundante, como apresenta também teores mais elevados nos principais componentes que exaltam o seu valor (1). Para verificação do comportamento da M. A. 701, com referência à época da colheita, foi feito um ensaio que produziu resultados bem valiosos. Um lote de $35 \mathrm{~m} \mathrm{x} 4 \mathrm{~m}$ foi, depois do primeiro corte, dividido em 15 canteiros, estabelecendo-se que a colheita seria feita em três épocas diferentes, com intervalo de cêrca de três semanas entre uma e outra.

A da primeira época efetuou-se a 5 de abril de 1949, exatamente três meses depois do primeiro corte ; a da época seguinte, a 26 do mesmo mês, e a terceira, a 24 de maio, retardada de uma semana, em virtude de causas fortuitas, vindo êsse fato tornar mais acentuado o declínio da produção, conforme se pode verificar no quadro 2.

A principal causa da diminuição da produção foi a queda das fôlhas, a qual se vai agravando à medida que a planta amadurece. Começam então a cair as situadas na parte inferior das hastes e a desfolha avança em direção à parte superior, para deixar apenas as fôlhas ponteiras.

Essa desfolhação é tanto mais acentuada quanto mais denso o "stand", isto 6 , maior a vizinhança entre as hastes. Constata-se que a var. "Campinas" M. A. 701 possui grande capacidade de brotação, a qual está correlacionada à sua prolificidade. Depois do primeiro corte, os rizomas brotam intensamente, emitindo numerosas hastes, que cobrem todo o terreno entre as fileiras (meadowmint), estabelecendo severa competição por espaço e luz. Esta circunstância favorece a queda das fôlhas da maneira já descrita.

Correspondentes a cada época, teríamos cinco amostras de óleo, de acôrdo com o número de canteiros, caso tivéssemos meios de fazer tôdas as destilações. Como não dispomos de instalações para fazer as destilações, em separado, das 15 amostras correspondentes aos 15 canteiros, foram reunidas as 5 de cada época e, desta forma, destiladas apenas 3.

Para ajudar a elucidar a composição do óleo essencial, coletamos, em separado, a primeira parte do destilado, dividindo-o assim em duas frações. Os dados referentes às produções, bem como às análises, figuram no quadro 2. 
Constata-se nesse quadro, com muita clareza, o seguinte : $a$ ) a menta "Campinas" M. A. 701 deve ser colhida madura, isto é, em pleno florescimento ; b) durante um período de 3 a 4 semanas, a contar do dia em que se pode dar como generalizada a floração, a qualidade do óleo melhora progressivamente, sem acarretar perda na produção ; $c$ ) os teores de mentona diminuem de maneira constante à medida que a erva amadurece; os de ésteres, ao contrário, aumentam enquanto os de mentol, depois de atingirem um máximo, entram em diminuição, sendo afetado principalmente o teor de mentol livre ; $d$ ) o aumento do teor de ésteres e diminuição da mentona beneficiam a qualidade da essência, porém há um limite natural que coincide com o nivel máximo da percentagem de mentol; $e$ ) nas plantações comerciais, a separação da "cabeça", ao se alambicar, constitui um recurso prático para melhorar a qualidade do óleo, quando a erva tiver de ser colhida antes da maturação.

QUadro 2.-Resultados analíticos de amostras de óleo de menta M. A. 701 obtidos em duas diferentes fases da destilação, de erva colhida em várias épocas

\begin{tabular}{|c|c|c|c|c|c|c|c|c|}
\hline Época da colheita & $\begin{array}{l}\text { Péso de } \\
\text { erva } \\
\text { verde }\end{array}$ & $\begin{array}{l}\text { Oleo } \\
\text { obtido }\end{array}$ & $\begin{array}{l}\text { Fração do } \\
\text { destilado }\end{array}$ & Ésteres & $\begin{array}{c}\text { Mentol } \\
\text { total }\end{array}$ & $\begin{array}{c}\text { Mentol } \\
\text { livre }\end{array}$ & $\begin{array}{l}\text { Men- } \\
\text { tona }\end{array}$ & $\begin{array}{c}\text { Indice } \\
\text { de } \\
\text { acides }\end{array}$ \\
\hline \multirow{3}{*}{ Primeira (5 abril 49) } & $k g$ & $\theta$ & $n .0^{\circ}$ & $\%$ & $\%$ & $\%$ & $\%$ & $\stackrel{m g}{K O H / g}$ \\
\hline & \multirow{2}{*}{118,0} & \multirow{2}{*}{430} & $\int$ Prımeira & 2,8 & 73,4 & 71,2 & 18,8 & 0,3 \\
\hline & & & L Segunda & 3,4 & 78,6 & 74,6 & 17,0 & 0,3 \\
\hline \multirow[t]{2}{*}{ Segunda (26 abril 49) } & \multirow{2}{*}{109,5} & \multirow{2}{*}{420} & Primeira & 4,1 & 80,4 & $\mathbf{7 7 , 2}$ & 17,0 & 0,3 \\
\hline & & & ( Segunda & 3,1 & 82,9 & 80,5 & $14, \tilde{0}$ & 0,7 \\
\hline \multirow[t]{2}{*}{ Terceira (24 maio 49) $\ldots$} & \multirow{2}{*}{95,4} & \multirow{2}{*}{285} & $\int$ Primeira & 5,1 & 79,2 & 75,2 & 13,0 & 0,8 \\
\hline & & & Segunda & 6,4 & 81,4 & 76,4 & 12,5 & 0,3 \\
\hline
\end{tabular}

\section{4-CARACTERISTICAS FÍSICO-QUÍMICAS DO ÓLEO ESSENCIAL DA M. A. 701}

O b́leo da var. "Campinas" M. A. 701 caracteriza-se pelo aroma agradável, por ser doce e mentolado. O seu teor em mentol é comparável ao da menta japonêsa comum, alcançando níveis elevados, acima de $80 \%$, quando a erva é colhida no correto estado de maturação (1). A soma mentol + mentona perfaz sempre mais de $90 \%$ dos componentes do óleo (quadro 3).

Os teores de mentol combinados em relação aos de mentol total (livre combinado), representam menos de $4 \%$, quando, na menta comum, é superior a $5 \%$.

Os cristais de mentol extraídos da essência da M. A. 701 são de purificação mais fácil e possuem aroma mais agradável. O óleo, do qual, pelo frio, foi parcialmente extraído o mentol, apresenta grandes diferenças na composição, quando pôsto em confronto com o similar obtido da menta japonêsa comum, notadamente no seu elevado teor em mentona e relativamente baixa taxa de ésteres. 


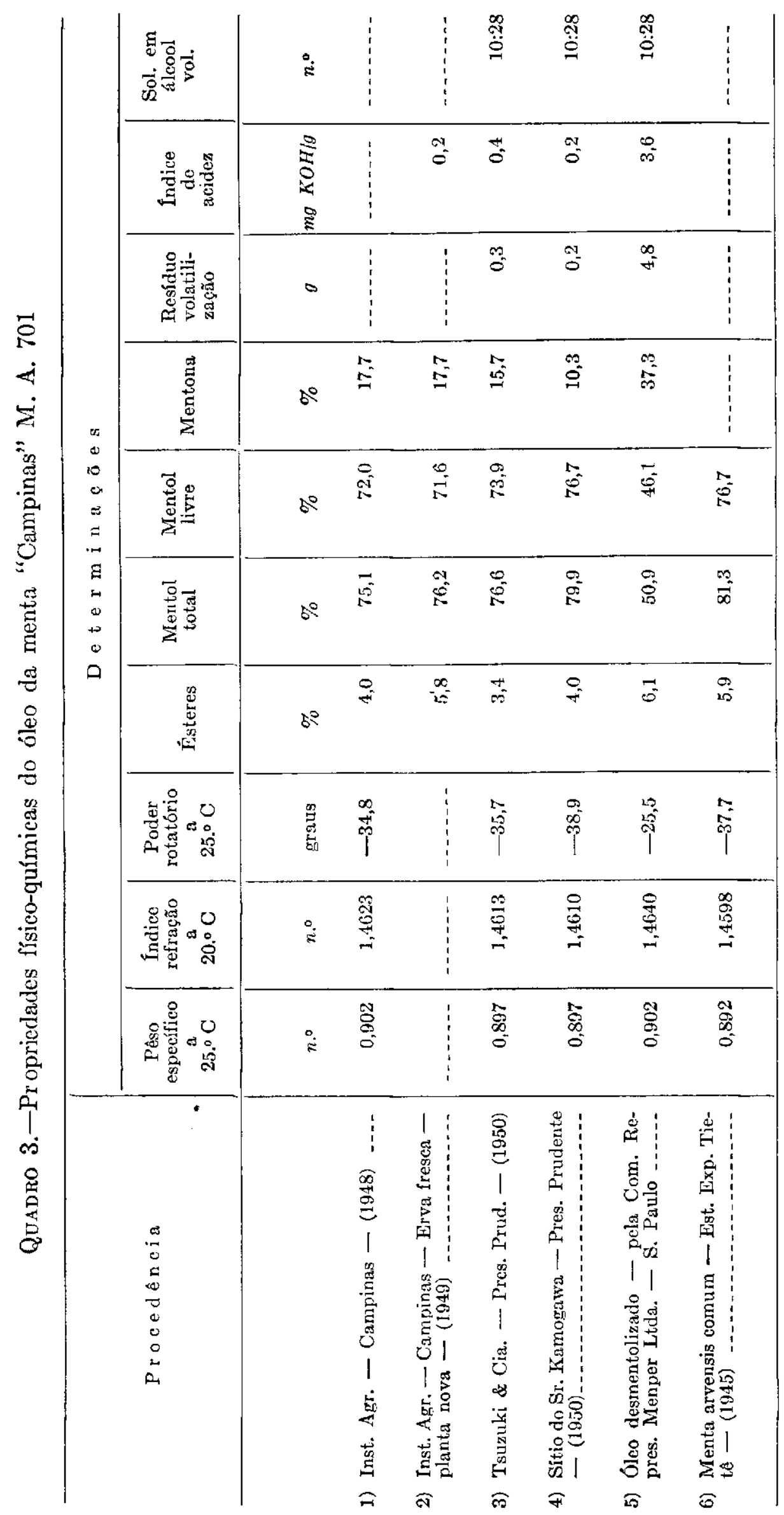


A riqueza em mentol tende a ser mais baixa, em consequência da maior facilidade da extração, sendo o limite de $50 \%$ muito elevado para êsse tipo de óleo desmentolizado natural.

Com uma retificação bem orientada, o bleo desmentolado, da var. "Campinas", poderá ser empregado em confeitaria, bebidas e outros preparados. A deficiência de aroma pode ser corrigida com a adição de essência da menta piperita (Mentha piperita L. var. vulgaris L.).

Fazendo-se a saponificação e o fracionamento, obtém-se uma fração com elevado teor de mentona e muito própria para o tratamento redutor, visando a obtenção do mentol sintético ou artificial.

Finalmente, devemos registrar a falta ainda existente de estudos quimicos detalhados, para melhor conhecimento da composição dêsse óleo essencial.

\section{RESUMO}

No quarto ano dos trabalhos de seleção com a menta japonêsa, foi encontrado um "seedling", o M. A. 701, que se destacou pela resistência a ferrugem e pela sua rusticidade.

Os caracteres botânicos dessa variedade comercial, principalmente hábito vegetativo, coloração das fôlhas e das hastes, a tornam completa. mente distinta da variedade original. Esta distinção se confirma e acentua quando se compara a natureza dos componentes do óleo essencial da menta "Campinas" M. A. 701, descrita no presente trabalho, com a menta japonêsa comum.

A maior produtividade da nova variedade comparada com a da menta japonêsa comum foi desde logo também constatada pelos primeiros lavradores, a quem foram enviadas pequenas quantidades de rizomas, para plantio experimental. Foram cultivados em 1949-50 cêrca de 12 hectares; em 1950-51, cêrca de 900 ha, e o prognóstico é que essa variedade tende a substituir totalmente a menta japonêsa anteriormente cultivada em São Paulo, devido ao seu maior valor econômico.

\section{SUMMARY}

A seedling, designated M.A.701, remarkable for its vigor and resistance to rust, was discovered during the fourth year of selection of Japanese mint (Mentha arvensis L. subsp. haplocalix Briquet var. piperascens Holmes or forma piperascens Malinvaud).

The botanical characters of the variety derived from this seedling, especially the vegetative habit and colouring of leaves and stems, make it quite different from the original variety. This difference is enhanced, when we compare the nature of the essential oil components of "Campinas" M.A.701, as described in the present paper, with that of the common Japanese mint.

The higher yield of the new variety, compared with that of the common Japanese mint, was soon confirmed by the first cultivators, to whom small quantities of rhizomes were sent for experimental planting. About 12 hectars were cultivated em 1949/50 and about 900 hectars in 1950/51. It is expected that the new variety will, on account of its greater economic value, tend to replace entirely the Japanese mint generally grown in the State of São Paulo. 


\section{LITERATURA CITADA}

1. Guenther, Ernest. Em. The essential oils, vol. 3, pag. 664-676, D. Van Nostrand Co. (New York). 1949.

2. Parry, Ernest J. Em. The chemistry of essential oils and artificial perfumes, vol. 1. Monographs on essential oils, 4." ed.pag. 212-230, Scott, Greenwood and Inc. (Londres). 1892.

3. Stellfeld, Carlos. A hortelã pimenta japonêsa. Trib. farm. Curitiba 9 : 23-28, 64, 1941. 